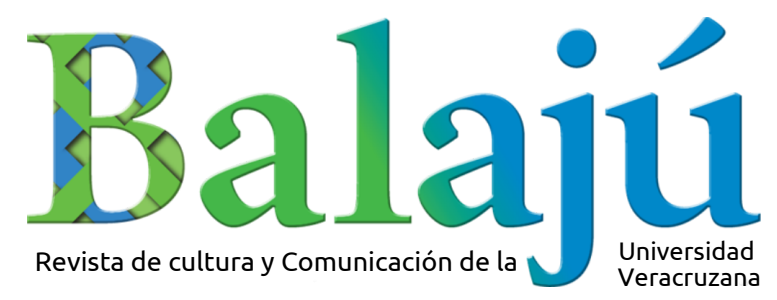

\title{
Cuestionar la revolución cubana desde la militancia: el cine de Sara Gómez
}

\section{Emmanuel Solís Pérez}

Universidad Veracruzana

Recibido: 28-05-2020 | Aprobado: 29-11-2020 


\title{
Balajú
}

\section{Cuestionar la Revolución cubana desde la militancia: el cine de Sara Gómez Questioning the Cuban Revolution from Within: The Cinema of Sara Gómez}

\author{
Emmanuel Solís Pérez ${ }^{1}$
}

\section{Resumen}

En este artículo se revisará parte del trabajo fílmico de la cineasta afrocubana Sara Gómez Yera, con el fin de exponer argumentos que la directora formuló pocos años después de la implementación del régimen revolucionario en Cuba. Su militancia y agudeza plasmadas en sus películas, casi todas de corta y de media duración, excepto su primer y único largometraje De cierta manera (1974), manifestaron el sentir de grupos excluidos en una sociedad devenida de procesos históricos complejos. Racismo, machismo, marginación y la asimilación de una identidad revolucionaria son algunas de las categorías que se pondrán en diálogo con elementos de la producción cinematográfica de esta cineasta en aras de reflexionar sobre la relevancia de su trabajo.

Palabras clave: Sara Gómez Yera, cine cubano, cortometraje

\begin{abstract}
This text explores selected films by Afro-Cuban director Sara Gómez Yera, made not long after the installation of the revolutionary regime in Cuba. The militancy and sharpness reflected in her films, almost all of which are short and medium length, except for her first and only feature film De cierta manera (1974), expressed the sentiments of long-excluded groups in a society emerging from complex historical processes. Racism, machismo, marginalization, and the assimilation of revolutionary identity are some of the categories put in dialogue with elements of her film production, in order to reflect on the continuing relevance of this filmmaker's work.
\end{abstract}

Keywords: Sara Gómez Yera, Cuban cinema, short film

\footnotetext{
${ }^{1}$ Universidad Veracruzana. ORCID: 0000-0002-6119-5986, emanuel.solis@gmail.com
} 


\title{
Balajú
}

\section{Cuestionar la Revolución Cubana DeSDE la Militancia: El CINE DE SARA GóMEZ}

\author{
Emmanuel Solís Pérez
}

El llamado Nuevo Cine Latinoamericano, que surgió a mediados del siglo XX, promovió una identidad unificadora en estas latitudes del continente, cuyas circunstancias sociopolíticas se presentaban al mismo tiempo distintas y similares: en más de una nación se instauró una dictadura militar, se sufrió el yugo del autoritarismo gubernamental o algún tipo de intervención extranjera. Eran tiempos con espíritu revolucionario, en los que emergieron resistencias hacia los regímenes capitalistas de economías liberales. En el plano cinematográfico, se realizaron encuentros como el Festival de Cine de Viña del Mar en 1967, donde convergieron intenciones comunes en torno al cine contestatario de América Latina. En este festival, además de difundir la producción regional, se buscaba fomentar la unión del gremio cinematográfico con la mira de dotar al pueblo de herramientas, por medio de las películas, para debatir, cuestionar y luchar ante la amenaza imperialista (King, 1994: 109).

Esta efervescencia social afincada en la reivindicación de las clases oprimidas encontró afinidad en las franjas populares e intelectuales, quienes reconocían la necesidad de crear un hombre nuevo, producto de un cambio revolucionario profundo. Los manifiestos radicales y reformadores que teorizaron cineastas cubanos como Tomás Gutiérrez Alea ("El free cinema y la objetividad", 1960) o Julio García Espinosa ("Por un cine imperfecto", 1969) clamaban el distanciamiento de los códigos occidentales en la manera de representar asuntos sociales en el cine, a la vez que llamaban a un renacimiento del arte en términos de colectividad entre artistas revolucionarios cercanos al proletariado. Fue así como "el cine cubano posrevolucionario subvirtió el fenómeno del cine como espectáculo" (Longueira Borrego y Hernández Zamora, 2019), bajo las intenciones políticas que buscaban derrocar las estructuras colonialistas para disolver diferencias primordialmente de clase.

El caso paradigmático de Cuba fue modelo a seguir para las vanguardias de pensamiento en la época. Aunque la Revolución cubana representó un triunfo social que animó el espíritu libertador en Latinoamérica, paradójicamente tendió a producir nuevas exclusiones conforme se instauraba (Soriano y Mullaly, 2014: 15). Quince años después del primero de enero de 1959, aún era notable el "mantenimiento de jerarquías etnorraciales, de género y de clase en la 


\section{Balajú}

nueva sociedad cubana" (Mullaly, 2019), pues hubo subestructuras culturales complejas de incorporar al proyecto socialista, que dejaron una impresión de inclusión parcial y pusieron en evidencia "la cambiante moral de una colectividad con fuentes contrarias en permanente cuestionamiento" (González, 2017: 11). Así también, las subdivisiones de lo marginal como sectores populares periféricos o afrocubanos representaron una complicación para la integración nacional; la homologación ciudadana fue una difícil encomienda debido a la diversidad cultural y a enormes diferencias sociales en la isla.

Estos tópicos no fueron soslayados por la comunidad artística e intelectual revolucionaria, quienes, desde una postura dialéctica, debatieron sobre la relación entre la cultura nacional y los cambios que experimentaba Cuba. Camila Valdés rescata las conclusiones de una serie de reuniones realizadas en 1963 por un grupo de cineastas e integrantes del Instituto Cubano del Arte e Industria Cinematográficos (ICAIC), organismo encargado de la producción fílmica en el régimen revolucionario. La intención principal era responder a cuestionamientos en torno a la interacción de los artistas con el pasado cultural de la isla para introducirlos en los esquemas didácticos del cine revolucionario. Se discutió la viabilidad del diálogo entre las culturas con posicionamientos ideológicos divergentes a los asumidos por la intelectualidad cubana comprometida con la joven revolución. En consenso, decidieron que no podía haber rechazo a lo que quedaba fuera de los ideales de la revolución; la vía factible era la apertura y la integración de todas las manifestaciones de la cultura. Dentro de estos cineastas estaba incluida Sara Gómez Yera (Valdés, 2016: 110).

Sara Gómez Yera fue una cineasta afrocubana que expuso las diferentes facetas de la otredad dentro de la revolución. Los temas y personajes con los que trabajó se enmarcan en el género documental, aunque su última cinta, De cierta manera (1974), se compone de una narrativa ficcional en diálogo con inserciones documentales. El soporte en prácticas etnográficas le permitió registrar sus inquietudes con una intención al mismo tiempo militante y crítica, cuando priorizó las reacciones y sentires que generaba la instauración del modelo revolucionario en grupos sociales poco atendidos por el nuevo régimen. Juan Antonio García Borrero, escritor y crítico de cine cubano, afirma que la osadía de la directora fue asomarse a la vida de los que no pertenecían al paradigma de hombre nuevo; describe el entusiasmo de la directora al saberse en un momento excepcional para la isla, pero aún la afiliación a los ideales de la revolución "no la estimulan a hacer del cine una operación simplemente apologética, que lejos de revelar los problemas de la realidad los ignore" (García, 2003: 185). Inés María 


\section{Balajú}

Martiatu, amiga de Sara Gómez en los tiempos del ICAIC, revela a Lourdes MartínezEchazábal en la entrevista plasmada en ;Sara es mucha Sara! que la cineasta, aunque revolucionaria, no fue incondicional ni acrítica ante el régimen, pues se mantuvo retando el triunfalismo por medio de un cine sociológico, negro, feminista y político (Martínez-Echazábal y Martiatu, 2014).

Son varias las aristas que colocan a esta cineasta como un caso excepcional para la cinematografía latinoamericana: además de presentar historias en las que subrayó los rasgos afrocubanos generalmente en estado de marginación, fue la primera mujer en filmar un largometraje en Cuba. Sin embargo, la particularidad más aguda del trabajo de Gómez Yera fue el compromiso político que expuso en dimensiones colectivas e individuales; desde la perspectiva de una mujer revolucionaria, planteó cuestionamientos incómodos para el régimen por medio del cine, un cine con rasgos feministas que mostró una "revolución dentro de otra revolución" y que debatió la posición de la mujer nueva, en alusión directa al término de Alexandra Kollontai, cuya condición equitativa al hombre sería necesaria para la destrucción del capitalismo y el arribo a la sociedad socialista (Álvarez Ramírez, 2015: 400). En buena parte de su trabajo fílmico, Sara Gómez presentó las contradicciones que se generaron entre las metas individuales de las mujeres y los deberes que la sociedad revolucionaria les exigía desde su condición de género, como ilustran explícitamente los documentales Atención prenatal (1972), Mi aporte (1972) y Sobre horas extras y trabajo voluntario (1973).

Este interés de la cineasta por mostrar historias que oscilaban entre lo individual y lo colectivo la motivó a desarrollar herramientas narrativas para estructurar relatos que mostraron un tejido social con texturas mixtas y contradictorias, narrativas horizontales y subjetivas centradas en actores sociales que atravesaban por cambios políticos en conflicto con sus circunstancias individuales. Sandra Abd'Allah-Álvarez describe el oficio cinematográfico de Sara Gómez "como si, más que hacer (...) documental, quisiera documentar un proceso, en toda su expresión y con todas sus contradicciones" (2013). Las implicaciones políticas de su discurso se filtraban por medio de la selección de testimonios que exploraban las relaciones humanas en transformación y evidenciaba "una nueva ética en una sociedad imperfecta, pero con empeño de perfeccionalidad" (Fulleda León, 1999). Sin recurrir a construcciones estéticas intrincadas, el cine que hizo Gómez Yera privilegió el momento social y no el arte cinematográfico en sí; para alcanzar este fin, las voces de sus personajes debían enunciar aspectos de su cotidianidad tal cual dictaba su realidad, sin concesiones al proyecto político, lo 


\section{Balajú}

que derivó en documentales que revelaron categorías culturales en tensión que aún continúan arraigadas en la sociedad cubana.

Bajo un ánimo sociológico, el repertorio temático de su trabajo documental no solo cubrió la desigualdad de género o las condiciones raciales y materiales de vida, incluidas sus expresiones más radicales como el machismo o la marginalidad, sino también se acercó a otras manifestaciones paradigmáticas en Cuba, como la religión de influencia africana y la diversidad de la cultura tradicional que, en algunos sectores como el afrocubano, se expresaba con mayor vigor en la música. Desarrolló un sentido de compromiso histórico por la cultura en constante confrontación con su presente, pues sus películas hoy pueden leerse en un plano reflexivo como "documentos analíticos que traen a debate los orígenes de la propia identidad" (Flores, 2014: 50). Por ello resulta pertinente identificar algunos tópicos en su trabajo fílmico, con miras a bosquejar el capital discursivo de esta directora. Por medio de la delimitación de estos temas cubiertos en su espectro cinematográfico, en conjunto con las técnicas narrativas que utilizó, se buscará delinear la manera en que el cine de Sara Gómez Yera construyó un discurso enfocado en intersecciones que tocan aspectos de clase, raza, género y cultura tradicional cubana.

Con base en el amplio espectro de contenidos que abordó la directora, plasmados en 19 películas, casi todos cortos y mediometrajes documentales, Lourdes Martínez-Echazábal (1994) categorizó esta producción en: documentales con características pedagógicas, que desarrolló principalmente en sus primeros ejercicios fílmicos dentro del ICAIC; documentales históricos-folklóricos, en los que revisa detalles de la cultura popular y la historia social de la isla; y documentales de carácter crítico social, en los que se percibe el tono contestatario alejado del triunfalismo revolucionario.

En este ejercicio se realizará una parcial revisión a la filmografía de Sara Gómez disponible en la plataforma YouTube, que representa solo una tercera parte de su producción. A partir de estos materiales compartidos por usuarios particulares no oficiales, se seleccionaron siete producciones en las que se tomó en cuenta la categorización de Martínez-Echazábal, agregando una categoría de tipo cronológico, que resultó en un ordenamiento en tres grupos: los trabajos tempranos, Plaza Vieja (1962), Iré a Santiago (1964) y Guanabacoa: crónica de mi familia (1966); la trilogía sobre la Isla de la Juventud, En la otra isla (1968), Una isla para Miguel (1968) e Isla del Tesoro (1969); finalmente, la exposición de algunos aspectos relevantes en estos cortos documentales servirá como antesala para el análisis de su película 


\section{Balajú}

De cierta manera (1974), que no pudo concluir ella misma debido a su intempestiva muerte en la etapa final de la filmación.

\section{Los trabajos tempranos}

Sara Gómez estuvo familiarizada con manifestaciones artísticas a lo largo de su vida. Muestra de ello fueron los estudios de piano que realizó en el Conservatorio de La Habana durante su infancia. ${ }^{2}$ Esta potente relación que mantuvo con la música es notoria en sus trabajos documentales, pues está presente en sus filmes para establecer un contexto histórico o para subrayar la fuerza de la cultura tradicional afrocubana. ${ }^{3}$ También incursionó en el periodismo durante su juventud por medio de colaboraciones en forma de reseñas de películas, de obras de teatro y de libros en la Revista Mella y en el semanario Hoy, oficio en el que probablemente desarrolló aptitudes para la escritura cinematográfica que nutrieron el carácter didáctico de sus primeros ejercicios audiovisuales. En sus tiempos de formación asistió al Seminario de Etnografía y Folklore que impartía Argeliers León en el Teatro Nacional de Cuba (Fulleda León, 1999). Estas sesiones le proporcionaron herramientas de aproximación a fenómenos sociales que influenciaron los tratamientos narrativos evidentes en su filmografía. Arropada con lecturas de Proust, Sartre, De Beauvoir, Camus y literatura sobre negritud, así como de experiencias personales como una estancia en el Bronx de Nueva York (Martínez-Echazábal y Martiatu, 2014), la directora desarrolló, desde muy joven, una conciencia racial y un nivel intelectual que suscitaron su integración como colaboradora del ICAIC en agosto de 1961.

Sus inicios en el cine fueron producciones para la Enciclopedia Popular, coordinada por Octavio Cortázar, miembro y compañero del ICAIC. La Enciclopedia fue una serie de cortometrajes compuestos por breves audiovisuales informativos que complementaban la campaña de alfabetización que impulsaba el régimen revolucionario en la isla. Plaza vieja (1962) fue el primer ejercicio que Gómez Yera filmó para esta serie; en este cortometraje pone de manifiesto su interés por la historia, al presentar una breve cronología de uno de los lugares emblemáticos de La Habana Vieja. El tono didáctico es evidente en la escritura de un guion claro y ameno, en el que utiliza su propia voz para narrar una crónica de esta plaza pública fundada en 1559.

\footnotetext{
${ }^{2}$ Datos extraídos de la biografía de Sara Gómez del sitio EcuRed: Enciclopedia colaborativa en red del gobierno de Cuba. https://www.ecured.cu/Sara_G\%C3\%B3mez

${ }^{3}$ Muestra de ello es el documental sobre la música tradicional cubana ...Y tenemos sabor (1967). Disponible en: https://youtu.be/XiRhLRmDYOg
} 


\section{Balajú}

Plaza vieja resume en breves minutos las transformaciones arquitectónicas y nominales del lugar, aderezadas con episodios trascendentes que acontecieron en este sitio de pasado colonial. Aunque es el primer acercamiento de Gómez Yera al cine, establece desde este cortometraje tópicos que la acompañarán durante su oficio cinematográfico: figuran en la narración el rol de la mujer en la historia, el pasado esclavista de Cuba y la música, tanto europea como regional. Como parte de una estrategia militante revolucionaria, este audiovisual concluye con una crítica al daño que generó la explotación del capitalismo en el espacio público y cómo el espíritu transformador del socialismo, apoyado por el trabajo de los jóvenes revolucionarios, restauraron la Plaza Vieja para devolverle el carácter solemne.

Acorde con Lourdes Martínez-Echazábal (2019), Sara Gómez rinde un homenaje a Santiago de Cuba y al poeta Federico García Lorca en su documental Iré a Santiago (1964), pues este título es una frase extraída del poema Son de negros en Cuba del escritor andaluz, cuyo fragmento abre el documental con el Son de la loma como acompañamiento musical ejecutado por el Santiaguísimo Trío Matamoros. En este cortometraje, considerado su primer trabajo cinematográfico en forma, la directora se toma licencias que sugieren madurez narrativa como una mayor extensión temporal, una marcada división en actos y un montaje dinámico con rápidos cortes. Se muestran a cuadro acciones cotidianas de la ciudad, espacios de relevancia histórica o festiva, acompañados por la voz de Natalia Nápoles que, como se establece en los créditos iniciales "comentario dicho por", más que narrar parece comentar las reflexiones plasmadas en el guion en torno a la ciudad. De la misma manera, en los créditos, la dirección se firma con el apelativo "Sarita" y en el cierre se menciona que es una producción del Departamento de Documentales, presumiblemente del ICAIC.

El documental subraya desde el inicio el carácter antillano de Santiago y la manera de exponer esta premisa es convidando del ritmo de la ciudad al espectador. La narración apunta "mulato es un estado de ánimo", mientras se muestran vistas de la actividad comercial en las calles y mercados o en la intimidad de las casas santiagueras (figura 1), que muestra los hogares afrodescendientes "ocupando un papel digno en el cine cubano y en un marco que siempre había estado excluido" (Martínez-Echazábal, 2019: 167). Estas vistas en las que se pronuncia la condición racial de los habitantes permiten construir un puente temático en torno a la herencia antillana de Santiago, al destacar que esta ciudad fue por donde entraron los primeros negros a Cuba. Se enfatiza la herencia colonial francesa de la ciudad, a causa de la migración 


\section{Balajú}

a Santiago de colonizadores francófonos y sus esclavos, quienes huyeron de la revolución en Haití.

Las mujeres ocupan espacios considerables en distintos aspectos del documental. En el plano artístico, se alude a la poeta romántica Gertrudis Gómez de Avellaneda, quien escribe el soneto Al partir, "sobre las aguas de Santiago". También se narra un mito popular sobre una mujer que se aparece en los bajos del fondo marino en traje de baño "deseando comunicarse"; esta secuencia es ilustrada con un montaje que presenta a una mujer en la playa, que aparece y desaparece con el efecto básico de corte directo, lo que tal vez revela el poco interés que la directora dedicaba a la imagen bajo los parámetros que promovía el cine imperfecto, ${ }^{4} \mathrm{o}$ tal vez era evidencia de la precariedad técnica en los recursos cinematográficos disponibles, que no eran abundantes desde la ruptura comercial que tuvo la isla con algunos centros de producción de insumos cinematográficos. Las relaciones de género en su dimensión cotidiana se exponen cuando se presentan al "santiaguero y la santiaguera", en un breve acto donde se hace partícipe al espectador de un cortejo resultado del deambular de ambos por las calles de la ciudad.

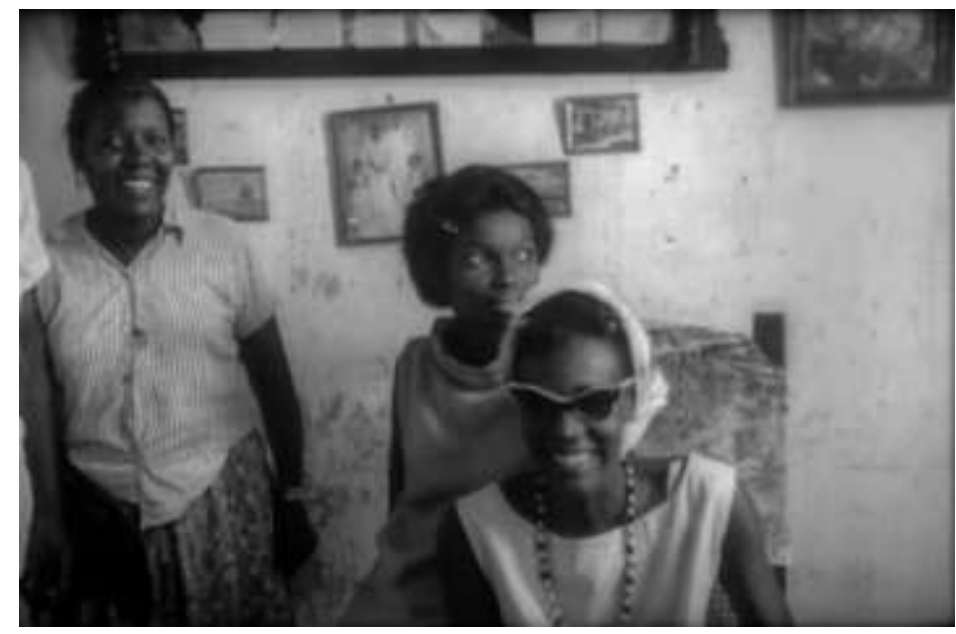

Figura 1. El interior de una casa de afrodescendientes santiagueros. Fotograma del documental Iré a Santiago (1964).

En este cortometraje no se percibe intención militante alguna; por el contrario, el discurso paródico envuelve una revisión profunda de ciertos conceptos fundacionales de la cubanidad,

\footnotetext{
${ }^{4}$ El cineasta Julio García Espinosa escribe en 1969 el manifiesto Por un cine imperfecto, en el que establece la naturaleza del arte y, en específico, del cine, que estaba en sintonía con el cambio revolucionario que se gestaba en Cuba. Este cine imperfecto debía contener una ideología que se opusiera radicalmente a las propuestas artísticas capitalistas, tenía una función y un compromiso político de ánimo militantes que buscaban establecer un lenguaje narrativo y poético centrado en las necesidades del pueblo.
} 


\section{Balajú}

que enfatiza el aporte caribeño de Santiago a la isla de Cuba. Lo más disruptivo en el documental es una larga secuencia final donde se presentan imágenes festivas de carnaval, baile y música, casi en un tono delirante. Como en Plaza Vieja, se reitera la música como elemento fundamental en las manifestaciones culturales populares; y en Iré a Santiago las canciones cubren un amplio rango de géneros afrocubanos: danzón, son montuno o el guaguancó. La música en la película se vuelve en muchos casos la mejor expresión de esa tradición popular resguardada, preservada en las capas marginales (Valdés, 2016: 114), muestra del "interés de la joven cineasta por la historia y la identidad de la diáspora africana en el Caribe, particularmente en Cuba" (Martínez-Echazábal, 2019: 162).

En 1966, Gómez Yera realiza el documental Guanabacoa: crónica de mi familia, un filme de corte personal en el que muestra su lugar de origen, un pueblo alejado del movimiento citadino. La intimidad también se percibe en una premisa coyuntural al comparar a dos mujeres de su círculo familiar a quienes admira: Madrina, una mujer mayor, hermana de su abuela; y su prima Berta, "una mujer sin complejos". Ambas mujeres representan generaciones distintas y la oposición entre el pasado prerrevolucionario con alta influencia europea y la Cuba contemporánea que encara una realidad muy distinta, a tono con las circunstancias del cambio.

La primera mitad del cortometraje transcurre sin narración, con un ánimo contemplativo hacia músicos en conciertos o ensayos, ejecutantes en una orquesta de tradición europea, quienes son identificados por sus nombres propios, lo que sugiere proximidad familiar con la realizadora. Conforme trascurre el documental, se asoman detalles del poblado hoy conurbado con La Habana. Estas imágenes se intercalan con inserciones de fotografías en marcos garigoleados, retratos familiares que indican antepasados de una época de refinamiento, posando solemnes y arropados con prendas de estilo europeo (figura 2). Con estos detalles la directora nos convida de su pasado privilegiado y educado, inserto en una sociedad de negros, pero "de ciertos negros", como lo subraya la narración, alejados de la pobreza y del analfabetismo pagano. Así lo constata la biografía y los testimonios de Madrina, quien a sus ochenta años se sigue manteniendo distante de las tradiciones populares del pueblo bajo un argumento plagado de conservadurismo católico. 


\section{Balajú}

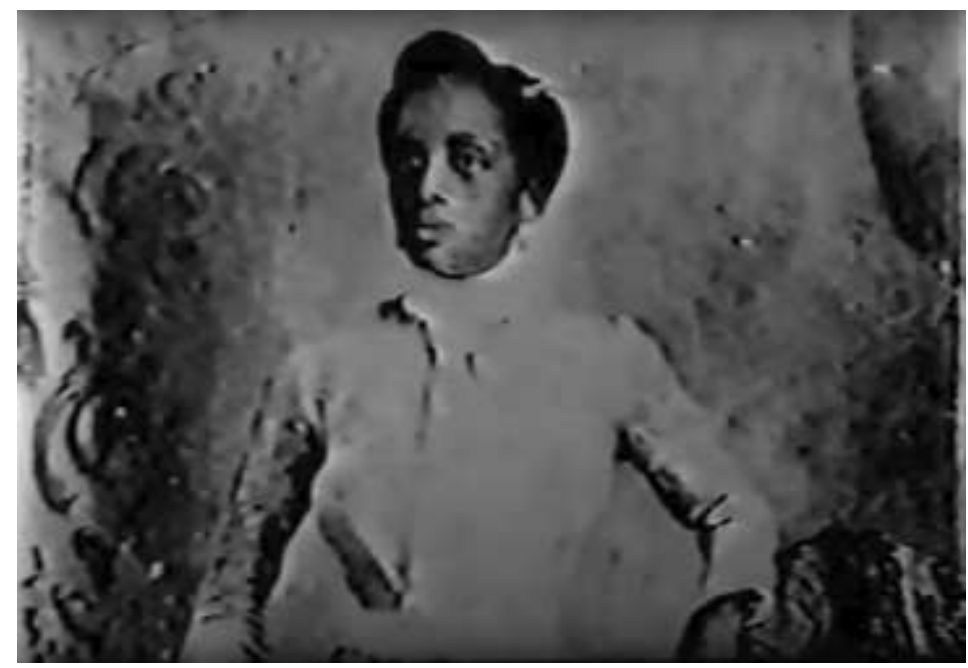

Figura 2. Un retrato familiar presentado en Guanabacoa: crónica de mi familia (1966).

Aunque la cineasta no expresa una crítica explícita a estas ambivalencias generacionales, presenta atinadamente dos momentos de Cuba a través de dos mujeres con realidades disímiles. El cambio de paradigma social que representó la revolución es reflexionado por la directora, quien no niega su pasado occidentalizado, aunque negro, pero también muestra afinidad con el cambio, sin atavismos culturales. El filme cierra con una pregunta que la cineasta se formula con su propia voz, en la que enfatiza esta oposición que se va agudizando a lo largo del corto: “¿Habrá que combatir la necesidad de ser un negro distinto, superado? ¿Venir a Guanabacoa aceptando una historia total, una Guanabacoa total y decirlo?”

Sara Gómez se va alejando gradualmente de su iniciativa militante para formular cuestionamientos que contrastan el peso histórico y cultural de la isla con la supuesta renovación social que demandaba el régimen socialista. Construye una crítica que no se fundamenta en un sentir reaccionario meramente político, sino a partir de la toma de conciencia de que la transformación podría implicar un proceso angustiante, y "expresar esa angustia será lo culturalmente válido". 5 Lo que puede identificarse como la etapa temprana de la artista demuestra un arraigado compromiso con esta disyuntiva, con la historia de su pueblo, con la revolución, con sus raíces africanas, con las mujeres cubanas.

\section{La Isla de la Juventud}

\footnotetext{
${ }^{5}$ Camila Valdés rescata en su artículo "De cierta manera. Lecturas de Frantz Fanon en Sara Gómez" (2016) la respuesta de la cineasta a una encuesta sobre el cine documental didáctico, propuesta por la revista Pensamiento Crítico (1970), núm. 42.
} 


\section{Balajú}

En la wiki colaborativa sobre temas cubanos, EcuRed, se encuentra una extensa descripción de esta isla, ${ }^{6}$ conocida desde tiempos antiguos como Isla de Pinos. El nombre Isla de la Juventud se le asignó en 1978 como un reconocimiento a los miles de jóvenes que respondieron a un llamado del régimen para rehabilitar la isla en ruinas a causa del paso de un huracán en 1966. Los jóvenes ocupantes de la isla realizaban tareas de reconstrucción, pero también adquirían una formación integral por medio de lecciones impartidas en los campamentos. Estos conocimientos eran complementados con el aprendizaje de actividades productivas primarias y oficios diversos que aplicaban en el mismo territorio. Sara Gómez filmó tres documentales en esta isla justo en este momento particular en 1968, año paradigmático para la juventud en varias ciudades del mundo.

En la otra isla (1968) es un documental en el que Gómez Yera aparentemente parece retomar sus intenciones militantes. Sin embargo, aplica una estrategia novedosa que se aleja del estilo utilizado en sus trabajos previos: en este filme, además de la narración, el hilo conductor del discurso lo dictan también los personajes: mujeres y hombres jóvenes hablan de sus actividades en la isla, de la vida en sus lugares de origen, de sus conocimientos y sus pasiones, de su fe y compromiso por la revolución. Escuchar estos testimonios genera una empatía inmediata con los personajes e ilustra la diversidad de contextos en los que el proceso de transformación de la conciencia era asimilado por una nueva generación. La isla de jóvenes derivó en "un lugar de reeducación y producción de verdaderos revolucionarios"; esta "reeducación supone en primera instancia una limpieza, un proceso de reculturación o sobreescritura en clave del hombre nuevo" (Longueira Borrego y Hernández Zamora, 2019).

Los intereses de la directora son evidentes en un par de guiños en el filme: hace una disertación sobre el racismo dentro del segmento titulado "Rafael cantaba", a partir de una entrevista con un joven afrodescendiente, cantante clásico formado en el Conservatorio de La Habana, quien confiesa a la directora la exclusión que sufrió en ese oficio debido a su condición racial. Este testimonio está dividido en dos partes; en la segunda de estas, cuando se narra el caso de discriminación, la directora se incorpora al plano compartiendo espacio con su interlocutor (figura 3). Esta acción nos remite al cine documental de modalidad participativa, según la catalogación de Bill Nichols (2013), cuando la directora, en un ejercicio etnográfico, muestra a cuadro la relación que construye con el sujeto filmado. Esta muestra de interés y

\footnotetext{
${ }^{6}$ Descripción disponible en: www.ecured.cu/Isla_de_la_Juventud
} 


\section{Balajú}

empatía ante las circunstancias personales de los jóvenes de la Isla de Pinos, así como el sentir proyectado en sus propias voces, se traduce como un llamado de atención a situaciones que, a pesar de estar contempladas en el proyecto socialista, generaron un sinfín de subjetividades en torno a la diferencia social en un esquema que aspiraba a la igualdad.

Otro énfasis que muestra la búsqueda de la cineasta se percibe con el tratamiento a la figura de la joven mujer revolucionaria. Gómez Yera pronuncia la participación de las jóvenes en el campamento, celebra su carácter rebelde y clama por la autonomía que deben asumir para las decisiones de toda índole, incluso sexual. La directora aprovecha el ambiente utópico de un mundo nuevo que representa la Isla de la Juventud para imaginar un contexto de equidad, en donde la inclusión preponderante de las mujeres devendrá en la consolidación de una generación completamente comunista.

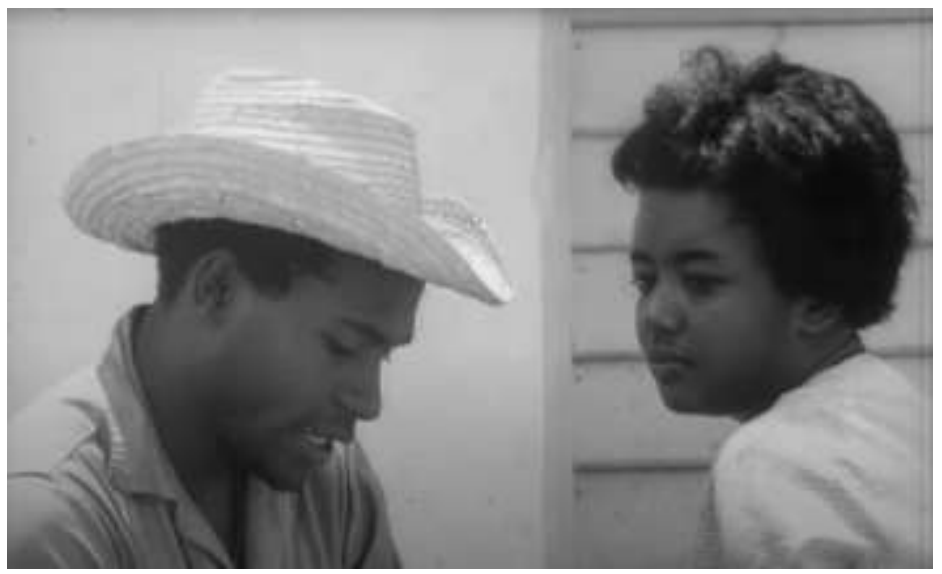

Figura 3. Sara Gómez dialoga con un personaje, en el documental En la otra isla (1968).

La experiencia en la Isla de la Juventud pareció ofrecer a la cineasta un cúmulo de historias que llamaron su atención. El cortometraje Una isla para Miguel (1968) es una muestra del interés que Gómez Yera continuó desarrollando, pues en este documental pone atención a las masculinidades que interactuaban en algunas secciones del campamento dentro de la isla. Una isla para Miguel es un relato narrado en el que se presenta un segmento específico de la isla, poblada por jóvenes entre los 13 y 17 años, quienes compartían la constante de tener "moral del barrio", que significaba "ser hombre, ser macho y ser amigo" (figura 4). La misión de los tutores adultos, agentes responsables de la supervisión en esta sección del campamento, expresada en sus testimonios, era conferirles a estos muchachos una ética de trabajo, tomando en cuenta que la mayoría de ellos venían de circunstancias sociales conflictivas. 


\section{Balajú}

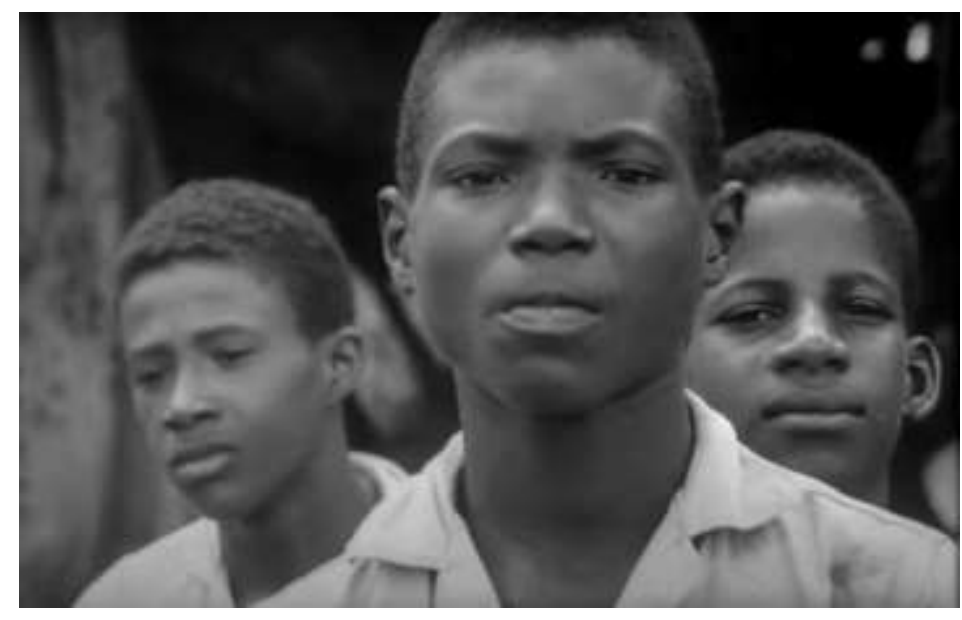

Figura 4. Jóvenes adolescentes en la Isla de Pinos. Cuadro del documental En la otra isla (1968).

El caso de Miguel es paradigmático, a juzgar por los testimonios y el registro visual que la directora incluye en la segunda parte del documental: la historia de un adolescente inquieto, proveniente de una familia numerosa que vive en condiciones marginales. La rebeldía y la actitud de Miguel se justifican cuando conocemos su contexto familiar; los pormenores de su entorno ponen de relieve que las situaciones precarias de los sectores populares afrodescendientes pueden fomentar la transmisión y la reproducción de conductas machistas y rebeldes. Como reiteración al vínculo racial, la música seleccionada remite al pasado tradicional afrocubano y se enfatiza en el cierre con una pieza musical compuesta de tambores, bongós, claves y una trompeta de jazz.

El registro en la Isla de la Juventud culminó con el corto La isla del tesoro (1969), en el que Gómez Yera hace un balance de varios elementos que conviven en la isla. ${ }^{7}$ El diálogo entre historia y presente se muestra por medio de numerosas vistas del paisaje, datos históricos que rememoran anécdotas de colonizadores y piratas, complementados con material de archivo que denota el carácter estratégico que tuvo la isla para fines comerciales de intereses extractivos. La narración femenina, una constante en el trabajo de la directora, ahora se acompaña de una voz masculina como representante del esquema patriarcal omnisapiente cuya interacción supone; más que un diálogo, una oposición entre ambos.

\footnotetext{
${ }^{7}$ Según la EcuRed: Enciclopedia Cubana en línea, la isla fue conocida también como Isla del Tesoro, en alusiones literarias que remiten a la constante circulación de piratas.
} 


\section{Balajú}

Una vez más, la impronta personal de la directora se manifiesta en escenas disruptivas que rompen lo lineal del discurso. La más provocadora, tanto por la representación audiovisual como por su carácter simbólico, es la presentación del Presidio Modelo, una cárcel monumental de tipo panóptico construida en esta isla. La directora escoge imágenes del desmantelamiento de esta prisión con un montaje abrupto y estridente, como metáfora sobre la necesaria destrucción para un nuevo renacer; sin embargo, la secuencia siguiente se compone de vistas en torno a la actividad industrial, la explotación de recursos naturales, la incorporación de maquinaria y la mano de obra a cargo de hombres negros, en directa alusión al esclavismo, un recordatorio de que aún con la demolición de viejas estructuras persisten aspectos problemáticos para suscitar progreso. Gómez Yera cierra este corto con los campamentos juveniles revolucionarios como parte viva de la isla e incluye inserciones de mujeres jóvenes con actividades en el campo, en una convivencia colectiva que nuevamente alude a un espíritu esperanzador en las nuevas generaciones revolucionarias.

En estos tres cortos documentales conviven historia, subjetividades juveniles, música, educación y construcción de ideología, aspectos que se empalman y que permiten al espectador reflexionar sobre el sentido simbólico que encierra la esencia del cine de Sara Gómez. En síntesis, la lectura de estos cortos sugiere que, además de la formación personal que propicia el espacio humano y que contribuye a crear interacciones sociales, el trabajo figura también como el motor que impulsa a individuos de nuevas generaciones a desarrollar de forma consciente y crítica relaciones más humanas con las cuales se sientan parte vital del proyecto revolucionario.

\section{De cierta manera (1974), una conclusión}

A los 31 años, Sara Gómez había construido un estilo cinematográfico agudo y potente, producto de un constante espíritu contestatario que la llevó a explorar diversos temas en conflicto por medio de sus aproximaciones documentales. Como se ha intentado plantear en este texto, son localizables ciertos tópicos que la directora exploró y desarrolló en formato de cortometraje por más de diez años, filmografía que se ve reflejada en la forma y el contenido de su primer largometraje, que paradójicamente es al mismo tiempo película póstuma. Existen varias particularidades en el primer y único largometraje de esta cineasta que llaman la atención. De cierta manera fue una filmación trastocada por la muerte de la directora en la fase 


\section{Balajú}

de culminación de la película, razón por la que tuvo que ser concluida por los cineastas Tomás Gutiérrez Alea y Julio García Espinosa, para finalmente proyectarse en 1977.

Es necesario enfatizar que el ICAIC produjo este largometraje y todos los cortometrajes que Sara Gómez realizó; por lo tanto, las discusiones que la directora abordó fueron generadas desde dentro del sistema socialista que repetidamente se mostró inflexible con críticos u opositores a su ideología. En este contexto, existe la impresión de que el trabajo de Sara Gómez no tuvo ni ha tenido la difusión necesaria en Cuba a causa de la poca complacencia que mostró al régimen, al grado de ser llamada "contrarrevolucionaria" (Martínez-Echazábal y Martiatu, 2014: 254). A pesar de los posibles obstáculos para difundir su trabajo, Gómez Yera encontró intersticios para exponer temas esenciales como la desigualdad social en las relaciones de raza y género en un régimen que suponía renovación; pero, como afirma Sandra del Valle en su artículo "Sara Gómez: lecciones de y para la Revolución”, “ser mujer (y ser una mujer negra) en la Cuba post-59 representaba (y aún sigue representando) enfrentarse a instituciones construidas sobre poderes patriarcales, que la Revolución, más que eliminar, reprodujo como parte de su lógica de poder" (Del Valle, 2013: 1).

De cierta manera es un docudrama escrito por la misma directora en colaboración con Tomás González, una propuesta innovadora que en su forma plantea el compromiso por una narrativa realista que se conjuga con la tradición documental. En dos capas discursivas en diálogo, la ficcional es el principal hilo conductor que muestra un encuentro de desigualdades, sociales y de género, la historia de la pareja conformada por Yolanda y Mario (figura 5), ciudadanos de contextos sociales diferentes cuyas vidas coinciden cuando ella comienza a trabajar en el barrio habanero de Miraflores, una zona suburbana marginal en transformación y lugar en el que habita Mario. La segunda capa con formato documental se inserta en momentos específicos para mostrar datos estadísticos sobre el espacio urbano y las acciones dedicadas al desarrollo de esas zonas periféricas. Gómez Yera recurre de nuevo a la metáfora visual que utilizó en La isla del tesoro, al insertar reiterativamente, en distintos momentos de la película, la imagen de las viejas estructuras inmobiliarias en demolición, para sugerir que un cambio estructural precisa de la destrucción de antiguos cimientos. 


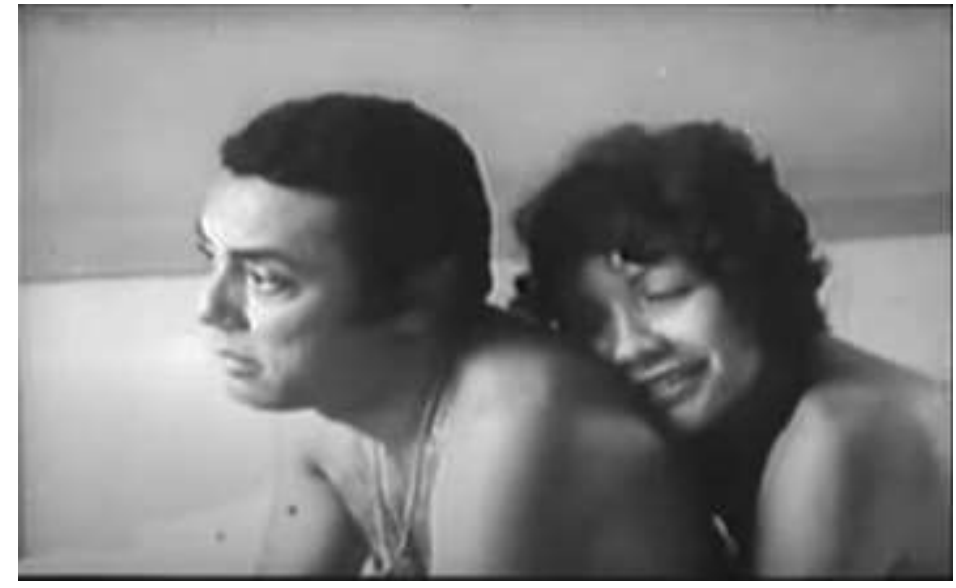

Figura 5. Mario y Yolanda, protagonistas de De cierta manera (1974).

Esta película presenta temas que Gómez Yera había explorado durante su filmografía, pero los expone con madurez técnica y agudeza discursiva, dando como resultado un filme complejo y provocador que pone en la mira las tensiones de la sociedad en la Cuba posrevolucionaria. Distintos tópicos se interceptan en un contexto de cambios, de revisión, de rupturas con el pasado opresor y capitalista, al mismo tiempo que se ponen en evidencia prácticas cotidianas generadas en estructuras culturales rígidas, difíciles de desmantelar. A continuación, se enlistan cuatro de estas tensiones identificadas como reiteraciones que la cineasta exploró tanto en $D e$ cierta manera como en sus cortos documentales:

Desigualdad de clase. En De cierta manera, Mario y Yolanda son los personajes principales, quienes inician una relación sentimental. Ella es una maestra de clase media habitante de La Habana, que llega a un barrio en la periferia para impartir clases en una escuela popular. En ese contexto conoce a Mario, un obrero nativo del barrio, con pocas oportunidades, quien durante la interacción con Yolanda se muestra agobiado por una serie de cuestionamientos personales sobre lo que significa ser hombre, ser revolucionario y sentirse inferior a su pareja. Las diferencias de clase no impiden que mantengan la relación, pero esta se desarrolla en medio de roces derivados de las distintas posturas que cada uno mantiene ante la efervescencia revolucionaria. El punto de vista progresista, racional y altivo de Yolanda se confronta con un Mario limitado, impotente, disminuido ante la fuerza intelectual de su pareja y ataviado por la necesidad de mantener su orgullo masculino fundado en una vida precaria. En esta relación dispar resulta paradójico observar cómo en medio de una transición al comunismo se mantuvieron o incluso se reforzaron las diferencias de clase. Entonces, ¿el hombre nиevo precisaba de cierto nivel de educación y de sensibilidad para abrazar 


\section{Balajú}

provechosamente el proceso revolucionario? ¿Qué sucedía con los adultos en las franjas de marginación que, a diferencia de los jóvenes, no tuvieron tantas oportunidades de reeducación o de reculturación?

Marginación. En su rol de maestra de enseñanza básica, Yolanda representa la juventud revolucionaria con la misión de alfabetizar a la sociedad cubana, incluso en las zonas más sensibles y desatendidas. La confrontación entre el espíritu de cambio y la complejidad de la realidad social se pone de manifiesto cuando Yolanda se encuentra con una serie de complicaciones en la escuela donde es maestra; acorde a su modelo pedagógico, siente la necesidad de ser exigente con los alumnos problemáticos y de expresar esa inquietud a los padres. Cuando se acerca a los contextos familiares de estos estudiantes se da cuenta de las complicadas situaciones en los sectores marginales. La realidad que confronta a Yolanda le obliga a entender que las iniciativas reformadoras y una actitud emprendedora no son suficientes para homogenizar las situaciones domésticas de cada niña y niño, en las que se presentan infinidad de irregularidades: padre ausente, pobreza, familias numerosas y demás rasgos que nos recuerdan las circunstancias de los muchachos campistas en la Isla de la Juventud.

Machismo. La directora pone especial atención a las interacciones que tienen los hombres obreros cuando discuten temas sobre honestidad y dignidad en el trabajo; esta pugna es una de las subhistorias desarrolladas en De cierta manera. Mario se debate entre asumir una actitud honesta para delatar a un amigo irresponsable y mentiroso, o apegarse al código de amistad y consentir las faltas del colega cercano. Para el sector obrero masculino es imposible olvidar la moral de barrio que se atisbó en Una isla para Miguel, donde la consigna "ser hombre, ser macho y ser amigo" adquiere una dimensión práctica. Sin embargo, esta postura masculina no se libra de las tensiones que implica el cambio hacia el hombre nuevo revolucionario, donde se encuentran en conflicto la dignidad y una complicidad "exaltada como gesto viril en los decretos no escritos del machismo" (González, 2017: 12-13). Otro guiño interesante en este rubro es la secuencia en la que Mario levanta en cólera porque esperó una hora a Yolanda para una cita; esta reacción violenta supone el fin de su relación, después de una álgida discusión donde quedan expuestas las incompatibilidades entre ambos. En medio de los constreñimientos entre géneros, Gómez Yera no se limita a señalar el machismo de la sociedad cubana: lo complejiza con aspectos contextuales que propiciaron y alimentaron 


\section{Balajú}

esa conducta opresora, construida en circunstancias sociales que deberían desmantelarse como las viejas estructuras pertenecientes a una época presuntamente superada.

Afrocubanidad. La condición racial es una constante agudamente estudiada por Sara Gómez en su cine y que se intersecta directamente con las categorías arriba mencionadas. Más allá de priorizar las historias de la población afrodescendiente en las narrativas por su peso cultural, estas también son presentadas en medio de contradicciones que el nuevo Estado cubano propició. Un ejemplo es la religión de influencia africana, cuyo potencial histórico y cultural es reconocido y exaltado por el régimen, pero al mismo tiempo se condenan ciertas prácticas de estos grupos por "ir contra el progreso" e incurrir en comportamientos de crueldad, criminalidad o inmoralidad. Además de la reiterada vinculación con la cultura popular y el énfasis dado a los personajes afrodescendientes, en De cierta manera hay un entrecruce que ocurre como desdoblamiento narrativo cuando la pareja se encuentra por la calle a Guillermo Díaz, un amigo de Mario, boxeador y músico tradicional afrocubano, cuya historia rompe la línea ficcional de la película para insertar un pasaje trágico y real de la vida de este personaje en la que asesina a un hombre. Además de las implicaciones de violencia, este fragmento hace alusión directa al potencial cultural cubano que reside en la música y se vincula a entornos marginales que se manifiestan en lo que se denomina "el ambiente", término que se refiere a la condición de fiestas y excesos en la que incurrían algunos ciudadanos en la época.

Otro momento explícito donde la negritud es señalada en De cierta manera sucede durante un diálogo entre Mario y Yolanda, cuando él relata pasajes de su infancia y juventud. Mario confiesa la intención que tuvo de convertirse en un ñáñigo, un miembro de la sociedad secreta Abakuá, culto religioso clandestino de ascendencia africana cuyo mito fundacional rechaza a las mujeres como miembros del grupo por considerarlas traidoras (MartínezEchazábal, 1994: 18). Mario enfatiza contundentemente que ese culto "lo hicieron los hombres y es cosa de hombres". Este diálogo es una muestra de cómo las intersecciones, entendidas como capas culturales diversas, determinan prácticas difíciles de erradicar si se piensan desde una praxis homogeneizadora, que soslaya condiciones específicas de algunos grupos sociales.

En la filmografía de Gómez Yera estas son solo algunas de las categorías que se pueden entender como leitmotivs, extraídos de entornos atravesados por lo que algunos autores han llamado cultura marginal, cuya estructura en el caso cubano no permitió que las reformas 


\section{Balajú}

sociales permearan a la base patriarcal y desigual que la caracteriza (Del Valle, 2013: 3). La teórica fílmica feminista Ann Kaplan formuló preguntas que aludieron al conflicto latente que el cine de Sara Gómez hizo visible después de instaurada la revolución en Cuba: “¿Cómo puede el individuo en proceso de cambio asumirse dentro de su tradición cultural, negativizada como marginal y atrasada, y ser a la vez crítico con ella?; ¿son acaso dos entidades apartadas las del ser revolucionario y las del ser hombre de barrio?" (Kaplan, 1998: 341). En la esencia de estas preguntas está implícito un entramado complejo, donde el cruce entre pobreza e identidad propiciaron una serie de variantes que mantuvo intactas prácticas de superioridad masculina, frente a las implicaciones del hombre nuevo revolucionario y los supuestos ideales de igualdad.

La condición de afrocubanos entró en constreñimiento durante estos procesos históricos, pues emergió un doble juego de identidades al reconocerse estos como entes revolucionarios latinoamericanos, pero desde la marginada condición afrodescendiente. Yissel Arce vincula acertadamente esta condición con la teoría sobre la "mímesis" propuesta por Homi Bhabha, en la que se homologan las características particulares de estos grupos, sin tomar en cuenta la historia de esclavismo o las estructuras culturales específicas en aras de una pretensión de equidad social (Arce, 2015: 62). Esta mímesis contribuyó a la homogenización de la sociedad para evitar poner en riesgo la revolución en tránsito; en el proyecto revolucionario no figuraron las particularidades y circunstancias de los sectores afrodescendientes, por lo que fue difícil que en Cuba se construyera la figura de un hombre negro nиevo.

La propuesta cinematográfica de esta cineasta excepcional revela esta constante tensión entre lo que se podía mostrar y lo que era preciso mantener oculto y marginado en el contexto revolucionario. Gómez Yera no tuvo reparo en exponer las dificultades que atravesaban las mujeres en una sociedad revolucionaria inevitablemente machista, ni en revisar los prejuicios y exclusiones que enfatizaban la diferencia racial, así como los intricados entornos que envolvían las circunstancias individuales. En esto consiste la emergencia del cine de Sara Gómez Yera, quien expresó la complejidad donde convergen pasado y presente de las prácticas colonialistas de Latinoamérica.

\section{Referencias}

ÁLVAREZ RAMÍREZ, Sandra Abd'Allah (2013). “Trascendencia de la obra cinematográfica de Sara Gómez", IPS Inter Press Service en Cuba, 27 de septiembre de 2013. 


\section{Balajú}

http://old.ipscuba.net/index.php?option=com_k2\&view=item\&id=8020:trascendencia -de-la-obra-cinematográfica-de-sara-gómez\&Itemid=11\&tmpl=component\&print=1

ÁLVAREZ RAMÍREZ, Sandra (2015). “El aporte de Sara Gómez”. En Afrocubanas, historia, pensamiento y prácticas culturales. Selección de Daisy Rubiera Castillo e Inés María Martiatu. La Habana: Instituto Cubano del Libro.

ARCE, Yissel (2015). "Relatos de exclusión. Indagaciones poscoloniales sobre raza y marginalidad en el cine de Sara Gómez”, Arte y Políticas de Identidad, 13, 59-78.

FLORES, Silvana (2014). "Mujeres emergentes en el cine político latinoamericano: los cortometrajes de Sara Gómez", Cinémas d'Amérique Latine, 22, 48-56.

FULLEDA LEÓN, Gerardo (1999). “QQuién eres tú Sara Gómez?”, La Gaceta de Cuba, 4, 4247.

GARCÍA BORRERO, Juan (2003). “Sara Gómez”. En Paulo Antonio Paranaguá (ed.), Cine documental en América Latina. Madrid: Cátedra.

GONZÁLEZ, Reynaldo (2017). "Sara Gómez: vivir y revivir en cine” (prólogo). Sara Gómez: un cine diferente. La Habana: Ediciones ICAIC.

KAPLAN, Ann (1998). Las mujeres y el cine. A ambos lados de la cámara. Trad. de María Luisa Rodríguez, Madrid: Cátedra.

KING, John (1994). El carrete mágico. Una historia del cine latinoamericano. Trad. de Gilberto Bello, Bogotá: TM Editores.

LONGUEIRA BORREGO, Nils y Yelsy HERNÁNDEZ ZAMORA (2019). "Islas dentro de la isla: repensando la 'otredad' en dos documentales de Sara Gómez”, LL Journal, 14 (2).

MARTÍNEZ-ECHAZÁBAL, Lourdes (1994). "The Politics of Afro-Cuban Religion in Contemporary Cuban Cinema”, Afro-Hispanic Review, 13 (1), 16-22.

MARTÍNEZ-ECHAZÁBAL, Lourdes (2019). "Santiago de dois peregrinos: Federico García Lorca e Sara Gómez em busca do oriente cubano". En Maria Aparecida Barbosa, Meritxell Hernando Marsal y Jair Tadeu da Fonseca (organizadores), Levantar bem alto um livro! Arquivo, tempo e imagem. Brazil: Rafael Competti, 155-182.

MARTÍNEZ-ECHAZÁBAL, Lourdes e Inés María MARTIATU (2014). "Sara es mucha Sara", Afro-Hispanic Review, 33 (1), 235-260.

MULLALY, Laurence (2019). "Rastros de la esclavitud en la sociedad cubana: la isla según Sara Gómez", Études Caribéennes, 4. 
NICHOLS, Bill (2013). Introducción al documental. Trad. de Miguel Bustos, México: UNAMCUEC.

SORIANO, Michèle y Laurence MULLALY (2014). "Introducción. De cierta manera: cuando las cineastas latinoamericanas reconfiguran las normas de género", De cierta manera. Cine y género en América Latina. Francia: L’Harmattan, 9-24.

VALDÉS, Camila (2016). "De cierta manera. Lecturas de Frantz Fanon en Sara Gómez”, Cuadernos del Caribe. Núm. 19, 45-51.

VALLE, Sandra del (2013). "Sara Gómez: lecciones de y para la Revolución", Cine Cubano, 187. https://n9.cl/203ps

\section{Cortometrajes de Sara Gómez disponibles en YouTube}

Plaza vieja (1962). Subido por Gerardo, 15 de agosto de 2011. 4:44. https://youtu.be/GXyxitHn2tc

Iré a Santiago (1964). Subido por Gerardo, 15 de agosto de 2011. 15:03. https://youtu.be/fNvf6zVZ2PI

Guanabacoa: crónica de mi familia (1966). Subido por Ale Waigandt, 15 de julio de 2019. 14:08. https://youtu.be/Mk-UuujlwoI

En la otra isla (1968). Subido por Jean Vallejo, 25 de agosto de 2003. 40:44, https://youtu.be/kOnBzj-0_Xc

Una isla para Miguel (1968). Subido por Gerardo, 21 de junio de 2011. 9:00. https://youtu.be/2YIiWoQOL4A

La isla del tesoro (1969). Subido por Gerardo, 14 de julio de 2011. 9:06. https://youtu.be/CvFJn0WH8s 